\title{
EQUATIVES AND DEFERRED REFERENCE
}

\author{
GREGORY WARD \\ Northwestern University
}

\begin{abstract}
Previous accounts of DEFERRED REFERENCE (e.g. Nunberg 1995) have argued that all (nonostensive) deferred reference is the result of MEANING TRANSFER, a shift in the sense of a nominal or predicate expression. An analysis of deferred equatives (I'm the pad thai) suggests an alternative account based on the notion of PRAGMATIC MAPPING: a contextually licensed mapping operation between (sets of) discourse entities, neither of which undergoes a transfer of meaning. Moreover, the use of a deferred equative requires the presence of a contextually licensed OPEN PROPOSITION whose instantiation encodes the particular mapping between entities, both of which remain accessible to varying degrees within the discourse model. Finally, it is shown how a complete account of deferred reference must provide for transfers of reference as well as sense.*
\end{abstract}

1. Introduction. One of the most creative, but least well understood, features of natural language is the possibility of DEFERRED REFERENCE (Nunberg 1977, 1979, 1995): the metonymic use of an expression to refer to an entity related to, but not denoted by, the conventional meaning of that expression. Various types of deferred reference-and the various linguistic mechanisms available for such reference-have been identified and discussed in the literature. To illustrate the range of possibilities, consider the following (now-classic) examples of deferred reference by means of a definite description, an indexical demonstrative, a proper name, and a mass noun in $1 \mathrm{a}-\mathrm{d}$, respectively.

(1) a. [server to co-worker in deli]

The ham sandwich is at Table 7. (Nunberg 1995, ex. 19)

b. [restaurant patron to valet, holding up a car key]

This is parked out back. (Nunberg 1995, ex. 1)

c. Yeats is still widely read. (Nunberg 1995, ex. 49)

d. The table is made of oak. (Nunberg 1995, ex. 24)

In 1a, the speaker's reference is deferred in the sense that she is referring indirectly to the person who ordered the ham sandwich via the ham sandwich itself. In $1 \mathrm{~b}$, the speaker refers indirectly to her car by an ostensive reference to the car's key, while in $1 \mathrm{c}$ the speaker is referring to the works of the poet via the poet himself. Finally, in $1 \mathrm{~d}$ the speaker refers to a particular kind of wood via the tree from which that wood is derived. The phenomenon of deferred reference has been intensively investigated in a number of frameworks and under a variety of labels (e.g. regular polysemy (Apresjan 1974), semantic transfer rules (Leech 1974), conventionalized correspondence rules (Jackendoff 1978), metonymy (Lakoff \& Johnson 1980), contextually based sense transfer (Sag 1981), active zones (Langacker 1984), lexical networks (Norvig \& Lakoff 1987), lexical implication rules (Ostler \& Atkins 1992), referential metonymy and

* I am indebted to Barbara Abbott, David Beaver, Tonia Bleam, Ann Bradlow, David Braun, David Dowty, Dan Grodner, Larry Horn, Nikki Keach, Jeff Kaplan, Chris Kennedy, Bill Lachman, Jeff Lidz, Yoshiko Matsumoto, Geoff Nunberg, Scott Schwenter, Elisa Sneed, Jason Stanley, Sam Tilsen, and especially Betty Birner for their valuable comments and assistance on earlier versions of this work. I am also grateful to Brian Joseph (editor of Language), Adele Goldberg (associate editor), and two anonymous referees for their many helpful comments and editorial assistance. An earlier-and much abridged-version of this paper was presented at the Vancouver Studies in Cognitive Science Workshop, held in February 2003 at the Simon Fraser University Harbour Centre in Vancouver, British Columbia and will appear in the proceedings of that workshop. I would like to thank the audience there as well as those at the University of Arizona, Temple University, The Ohio State University, Stanford University, the University at Buffalo, and the University of Rochester, where previous versions of this work were presented. 
predicative metonymy (Stallard 1993), connectors (Fauconnier 1994), meaning transfer (Nunberg 1995), constructional polysemy and sense extension (Copestake \& Briscoe 1995), logical metonymy (Pustejovsky 1995, Verspoor 1997), enriched composition (Jackendoff 2002), inter alia).

Much less studied, however, is the possibility of deferred reference with copular sentences of the form NP-be-NP, so-called equative sentences or identity statements, as illustrated by the naturally occurring examples in $2{ }^{1}$

(2) a. [customer to server holding tray full of dinner orders at a Thai restaurant] I'm the pad thai. (BL, in conversation, 8/10/02)

b. Samir Abd al-Aziz al-Najim is the four of clubs. (Chicago Tribune, 4/ 19/03, p. 5)

c. [physician assigning interns to patients]

You and you are shortness of breath. You and you take vertigo. And last but not least, knee pain. (ER, 4/24/03)

With the equative sentences in 2 , the speaker is equating the referents of the two NPs in order to convey a particular correspondence between them. In 2a, the speaker identifies himself with his dinner order to convey indirectly that he is the person who ordered pad thai. In $2 b$, the reporter is identifying which playing card bears the picture of alNajim, the former Iraqi Ba'th Party regional command chairman for East Baghdad. Finally, in 2c, the speaker, the supervisor of a hospital's emergency room, assigns interns to patients via the symptoms displayed by the latter. In the spirit of Nunberg's earlier work (1977, 1979), I refer to such equatives as DEFERRED EQUATIVEs. ${ }^{2}$

In this article, I present a pragmatic analysis of deferred equatives, showing how they constitute a distinct type of deferred reference. First, I argue that previous accounts, in not distinguishing between deferred equatives and nonequatives, have failed to identify and explain the distinctive properties of the former, and that theories of deferred reference will have to be revised in light of these facts. Specifically, I claim that the felicitous use of deferred equatives requires the presence of a contextually salient correspondence, or PRAGMATIC MAPPING, to hold between sets of relevant discourse entities (compare Nunberg's (1995) notion of FUNCTIONAL CORRESPONDENCE). In 2a, for example, the relevant mapping is between restaurant customers (set 1) and their orders (set 2). A crucial difference between the equative in $2 \mathrm{a}$ and the nonequative in, say, $1 \mathrm{a}$ is that with deferred equatives both of the mapped entities are EXPLICITLY evoked within the equative and, consequently, their meanings remain intact, that is, Nondeferred.

Second, contrary to previous studies in which all deferred reference requires a 'transfer' of the semantic sense of a nominal or predicate, I argue that in the case of deferred equatives the deferred interpretation is the result of a shift in meaning of the copula alone. Moreover, I maintain that in the case of some, but not all, deferred Nonequatives the relevant transfer is one of reference and not sense. Thus, a complete and adequate account of deferred reference will require both transfers of senses (à la Nunberg) and transfers of reference (à la Ward), with deferred equatives involving neither. In addition, the felicitous use of a deferred equative requires the presence of a contextually licensed OPEN PROPOSITION whose instantiation encodes the particular mapping between entities.

\footnotetext{
${ }^{1}$ In using the term EQUATIVE for equative copular sentences of the form NP-be-NP, I am following the terminology and analysis of Heycock and Kroch (1997) (but compare Higgins 1979), yet nothing in what follows depends on this particular syntactic analysis.

${ }^{2}$ This term is slightly misleading in that, as will become clear, I argue that what makes deferred equatives 'deferred' is a shift in copular meaning rather than a shift in the interpretation of either of the copular NPs.
} 
Finally, I identify a number of pragmatic constraints on the use and interpretation of deferred equatives and present the results of a psycholinguistic experiment that provide some empirical support for this analysis.

2. BACKGROUND. As a quarter of a century of scholarship attests, the locus classicus of work on deferred reference is Nunberg 1977, which provided the first systematic and comprehensive account of the sort of linguistic metonymy illustrated in 1 , that is, the use of a linguistic expression to refer to something not denoted by the conventional meaning of that expression. In his earlier work, Nunberg argued that such deferred interpretations are the result of a transfer of reference from one discourse referent (e.g. a ham sandwich) to another (the orderer of that sandwich). In his more recent work, Nunberg argues that the transfer mechanism applies not to the referents of linguistic expressions, but to their senses. Nunberg provides an account based on the notion of MEANING TRANSFER: ' $\mathrm{t}$ ] he name of a property that applies to something in one domain can sometimes be used as the name of a property in another domain, provided the two properties correspond in a certain way' (1995:111). Linguistically, these properties can be supplied by predicates of any semantic kind (e.g. attributive, predicative) and in any syntactic position (e.g. within the VP, within the subject NP). Nunberg identifies two basic linguistic mechanisms for meaning transfer: predicate (VP) transfer and common noun $(\mathrm{N})$ transfer. These two types are illustrated in $3 \mathrm{a}$ and $3 \mathrm{~b}$.

(3) a. Predicate transfer

I'm parked out back. $\rightarrow$ 'I'm the owner of a car parked out back.' (Nunberg 1995, ex. 2)

b. Common noun transfer

The ham sandwich is at Table 7. $\rightarrow$ 'The ham sandwich orderer is at Table 7.' (Nunberg 1995, ex. 19)

In predicate transfer, the predicate supplies the property to which the transfer applies. For example, the VP be parked out back in 3a provides a property of 'being parked out back', the meaning of which undergoes a transfer to the property of 'being someone whose car is parked out back'. Such a transfer would be licensed, say, in the context of a valet locating a car belonging to a customer. In the case of nominal transfer, the property is supplied by a common noun-ham sandwich in $3 \mathrm{~b}$-which then undergoes transfer to the property of 'being the person who ordered a ham sandwich'. This transfer would be relevant in the context of a server referring to a particular customer. Thus, under Nunberg's account, the relevant relationship is between predicates and properties and not between (sets of) discourse entities. Consistent with that view, Nunberg explicitly claims that the referent of the NP is 'not involved in the interpretation of the utterance' (1995:115), only the relevant property or predicate associated with the common noun within that NP is. Thus, for Nunberg, there is no ham sandwich on the table, so to speak, in the use of $3 b$ to refer to the orderer of the ham sandwich. In other words, the transfer is one of SENSE and not REFERENCE. ${ }^{3}$

Working within his theory of MENTAL SPACES, Fauconnier (1994) takes a somewhat different approach, one based not on transferred properties or predicates, but on Nunberg's notion of PRAGMATIC FUNCTION. For Fauconnier, deferred reference is the result

\footnotetext{
${ }^{3}$ The notion of REFERENCE TRANSFER (as opposed to sense transfer) was initially considered by Nunberg (1977, 1979) but was subsequently rejected by Nunberg (1995) in light of Sag 1981 and other reasons that will be explored in what follows. The notion is similar in spirit to Stallard's (1993) notion of REFERENTIAL METONYMY and Fauconnier's (1994) IDENTIFICATION PRINCIPLE, described below.
} 
of there being a pragmatically appropriate CONNECTOR, or link, between two (or more) objects. ${ }^{4}$ Such links are established 'for psychological, cultural, or locally pragmatic reasons' and, once established, 'allow reference to one object in terms of another appropriately linked to it' (1994:3). The culturally significant correspondence between restaurant customers and their orders is one type of pragmatic function. In this case, the description of the food order constitutes the TRIGGER, which is then linked to its corresponding TARGET, that is, the customer who placed that order. Figure 1 illustrates this relationship.

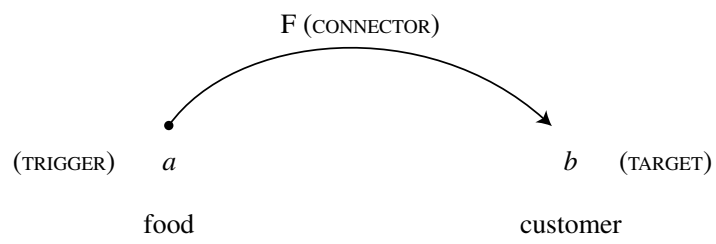

FIGURE 1. Deferred reference in a mental space (Fauconnier 1994, Figure 1.4).

In Fauconnier's system, the ham sandwich in $3 \mathrm{~b}$ would serve as the trigger for the application of a connector, which links the trigger to the corresponding target. In this way, the ham sandwich is 'linked' to the individual who ordered it. Note that neither Nunberg nor Fauconnier distinguishes between equatives and nonequatives within their respective theories of deferred reference; indeed, Nunberg provides 4 as an unexceptional example of nominal transfer applying to the definite description in predicate position. ${ }^{5}$

(4) I am the ham sandwich and I'd like it right now. (Nunberg 1995, n. 13, ex (i))

An obvious difference between the two approaches is that in Nunberg's system there are two avenues for deferred reference while in Fauconnier's there appears to be only one. Thus, one consequence of Nunberg's account based on meaning transfer is that, in the case of deferred equatives consisting of two definite descriptions, one in subject position, the other in predicate position, the relevant property could, in principle, result from either nominal transfer on the subject $\mathrm{N}$ or predicate transfer on the VP, as seen in $5 \mathrm{a}-\mathrm{b}{ }^{6}$

\footnotetext{
${ }^{4}$ For Fauconnier, an 'object' is meant to be interpreted 'in the most general sense' (1994:3); objects can be persons, descriptions, bodies, words, representations, and so forth.

${ }^{5}$ At issue for Nunberg here is the interpretation of the pronoun $i t$, not the equative per se.

${ }^{6}$ There is, of course, a third possibility that is not relevant to the current discussion: nominal transfer on the predicate $\mathrm{N}$ within the VP, as in (i).
}

(i) The man at Table 7 is the ham sandwich. $\rightarrow$ 'The man at Table 7 is the ham sandwich orderer.' Moreover, an utterance can in principle undergo вотн predicate and nominal transfer simultaneously (although Nunberg does not discuss this possibility). In fact, the subjects in our experiment (described below) judged such 'double transfers' (exemplified in (ii)) to be quite felicitous.

(ii) Two elderly gentlemen are regulars at Joe's Coffee Shop. One always orders a ham sandwich and the other always orders a BLT. You'd never know they are both very wealthy-one drives a Mercedes and the other drives a Rolls Royce. While on a break, two waitresses from Joe's, one of whom is a trainee, go outside for a smoke. They notice two cars with their lights on and one of them is a Rolls Royce. The waitress says to the trainee:

$\rightarrow$ The Rolls Royce is the ham sandwich.

Following Nunberg, the target utterance would undergo two meaning transfers, resulting in 'The Rolls Royce driver is the ham sandwich orderer'. 
(5) a. The man at Table 7 is the ham sandwich. $\rightarrow$ 'The order of the man at Table 7 is the ham sandwich.' (nominal transfer)

b. The man at Table 7 is the ham sandwich. $\rightarrow$ 'The man at Table 7 is the ham sandwich orderer.' (predicate transfer)

However, in the case of deferred equatives with no definite descriptions, Nunberg's nominal transfer mechanism is presumably unavailable given the absence of a common noun upon which to base the transfer. Consider the proper name equative in 6 .

(6) [family members discussing Secret Santa assignments] Who'd you get? I'm Anne.

Here, neither the pronominal subject NP $(I)$ nor the predicate proper name NP (Anne) lends itself to a nominal transfer. Thus, the only mechanism available would be predicate transfer, as in 7, in which the predicate be Anne would supply the relevant property of 'being Anne' and would undergo a meaning transfer to provide the property of 'being the family member assigned to Anne'.

(7) I'm Anne. $\rightarrow$ 'I'm the family member assigned to Anne.'

For Nunberg, then, the deferred equative in 4, I am the ham sandwich, is taken to be the result of nominal transfer whereas the deferred equative in 7, I'm Anne, is the result of predicate transfer. Thus, under a theory of meaning transfer, very similar constructions and uses receive quite different semantic analyses.

Within Fauconnier's theory of connectors and links, however, both constructions would presumably be the result of a single mechanism, that is, the function that links one discourse entity to another. For reasons that will become clear shortly, Nunberg explicitly rejects an analysis of this sort in which referring expressions (e.g. full NPs) undergo reference transfer from one discourse entity to another. Fauconnier's system, though, does permit such reference transfer, that is, a direct link between two discourse entities. What both frameworks have in common is that deferred equatives like those in 2 involve 'indirect reference' to something not explicitly evoked in the context. In what follows, I present evidence in favor of the notion of reference transfer, pace Nunberg, as well as evidence in favor of a nontransferred analysis for deferred equatives, pace Nunberg and Fauconnier.

3. SENSE TRANSFER vS. REFERENCE TRANSFER. It is clear from the work of Nunberg and others that some kind of mechanism for sense transfer is required. To illustrate briefly, consider 8 .

(8) This table is made of oak. [ $=1 \mathrm{~d}]$

It seems clear that the bare $\mathrm{N}$ oak here undergoes a shift in sense from '(a) tree of the genus Quercus' to 'wood derived from a tree of the genus Quercus'. What is less clear is whether ALL deferred reference can be reduced to a single mechanism of this sort, as Nunberg has argued. I suggest that in addition to sense transfer, an adequate account of deferred reference must also allow for the possibility of reference transfer.

In support of sense transfer and against reference transfer, Nunberg (and others) have offered a number of arguments; these are listed in 9.

(9) - number clash

- reference to the (non)deferred referent

- reflexives, bound anaphora, and quantification

In the remainder of this section I identify some problems with each of these arguments for sense transfer, especially as they apply to deferred equatives. I argue that at least 
some of these arguments, when cast in a new light, actually provide support in favor of the alternative notion of reference transfer. ${ }^{7}$

3.1. Number CLASH. In support of nominal sense transfer, Nunberg (1995) provides examples of number clash, as in 10.

(10) That (*those) french fries is (*are) getting impatient. (Nunberg 1995, ex. 20; judgments in the original)

Recall that, under Nunberg's analysis, there are two possible deferred interpretations: one involving nominal transfer on french fries (to 'orderer of french fries') and one involving predicate transfer on be getting impatient (to 'be the order of the person who is getting impatient'), analogous to the two interpretations of the ham sandwich example in 5. But Nunberg rules out predicate transfer in 10 on the grounds that the (nontransferred) plural subject (french fries) would force plural agreement with the predicate, which, as 11 shows, is infelicitous.

(11) \#Those french fries are getting impatient. $\rightarrow$ 'Those french fries are the order of the person who is getting impatient.'

That is, to get the deferred interpretation with predicate transfer, the subject nominal (those french fries) would have to remain untransferred (and plural), and with plural verb agreement the result is infelicitous. With predicate transfer ruled out, Nunberg must analyze 10 as an instance of nominal transfer, in which the presence of the demonstrative determiner, grammatically marked for number, forces agreement with the head noun. In the case of french fries, the head noun is plural, but its corresponding deferred meaning ('orderer') is singular. This leads to the possibility of a number clash between the deferred and nondeferred interpretations, as illustrated in 12.

(12) a. That french fries is getting impatient. $\rightarrow$ 'That orderer of french fries is getting impatient.'

b. *Those french fries are getting impatient. $\rightarrow{ }^{*}$ 'Those orderer of french fries are getting impatient.'

Since the grammatical number of both the determiner (that) and the verb (is) in 10 agrees with that of the transferred property (as in 12a) and not with that of the plural nominal (as in 12b), Nunberg concludes that transfer applies to the meaning of the common noun-and not the full NP.

There is, however, another-and simpler-explanation for the (relative) acceptability of 12a: french fries is being used here to denote a unit of food and NOT a plurality of objects, as illustrated in the service encounter in 13.

(13) Server: May I take your order?

Customer: A large fries, two milks, and three chicken nuggets. $\rightarrow$ 'A large order of fries, two cartons of milk, and three orders of chicken nuggets.'

As is well known, nouns that are canonically collective and plural (e.g. french fries, chicken nuggets) or mass and singular (e.g. milk) can be unitized into countable (and grammatically singular) nouns. ${ }^{8}$ Thus, a noun like french fries is not a good candidate

\footnotetext{
${ }^{7}$ As both Nunberg (1995) and Sag (1981) note, some kind of reference mapping mechanism is needed independently to account for the felicity of deferred reference with indexical demonstratives, as in (i).

(i) This is parked out back. [ $=1 \mathrm{~b}]$

${ }^{8}$ Speakers disagree about the felicity of less clearly unitized types of determiner-noun mismatches:

(i) That/those black-eyed peas at Table 7 is/*are getting impatient.

(ii) That/those lima beans over there needs/*need another napkin.
}

Although speakers are divided about which form of the demonstrative they would use, no speaker accepts a plural verb in this context. 
for seeing whether meaning transfer has applied. A better test case would be pluralia tantum nouns like pliers, tongs, tweezers, glasses, pajamas, or shorts, that is, grammatically plural nouns that denote single objects. Unlike unitized nouns like french fries, pluralia tanta in deferred reference constructions do display a number clash between a singular demonstrative and a plural noun, contrary to the predictions of an account based solely on sense transfer.

(14) a. \#I think that that shorts over there is pretty cute. $\rightarrow$ 'I think that that person wearing shorts over there is pretty cute.'

b. \#That pliers you were talking to now wants to know where we keep the power tools. $\rightarrow$ 'That person you were talking to who bought the pliers now wants to know where we keep the power tools.'

c. \#I wouldn't mind going out with that sunglasses at Table 7. $\rightarrow$ 'I wouldn't mind going out with that person wearing sunglasses at Table 7.'

Deferred reference here to a singular referent should be perfectly felicitous if meaning transfer applies to the italicized common nouns in these examples. That it is the number clash and not plurality per se that accounts for the infelicity of these examples is illustrated by 15 .

(15) a. I think that the shorts over there is pretty cute. $\rightarrow$ 'I think that the person wearing shorts over there is pretty cute.'

b. The pliers you were talking to now wants to know where we keep the power tools. $\rightarrow$ 'The person you were talking to who bought the pliers now wants to know where we keep the power tools.'

c. I wouldn't mind going out with the sunglasses at Table 7 . $\rightarrow$ 'I wouldn't mind going out with the person wearing sunglasses at Table 7.'

Here, there is no number clash between the article and the plural noun, and the resulting examples are felicitous. Thus it would appear that what blocks felicitous deferred reference in 14 is the number clash between the singular demonstrative determiner and the plural common noun and not between the plural common noun and the singular target.

The only exception to the prohibition against a number clash between determiner and noun seems to be plural nouns that are modified by an explicit number, as in 16a. ${ }^{9}$

(16) a. [bartender to cocktail waitress]

That sure was a long break you were on. The place is a zoo! The guy in the plaid shirt just puked in the bathroom. The gin and tonic in the corner is hitting on anything in a skirt, the chardonnay next to him pinched me twice, and that three martinis you're so fond of is about to pass out on the floor.

b. [bartender to cocktail waitress]

That sure was a long break you were on. The place is a zoo! The guy in the plaid shirt just puked in the bathroom. The gin and tonic in the corner is hitting on anything in a skirt, the chardonnay next to him pinched me twice, \#and that martinis you're so fond of is about to pass out on the floor.

In 16a, the addition of an explicit numeric modifier mediates the number clash between the demonstrative and the noun. Note the crucial role played by the numeric modifier in this example; without it, deferred reference to the martini drinker is infelicitous, as

${ }^{9}$ With a plural subject and a plural order, the deferred interpretation is completely felicitous, as in (i).

(i) Those two steaks are getting impatient.

However, the felicity of (i) can be accounted for either as a case of Nunbergian meaning transfer (on the $\mathrm{N}$ ), OR a shift in reference from one discourse entity to another, as argued here. 
shown in 16b. And it is clear that plurality in this example is associated with the trigger and not the target, undermining Nunberg's argument that meaning transfer is based on the common noun with plurality being a feature of the deferred referent alone. This is especially clear when the trigger appears in object position, obviating the awkward subject-verb agreement that results from a plural subject NP and singular verbal agreement.

(17) [customer to friend leering at pancake-eating customer in coffee shop] I wouldn't mind some quality time with those pancakes over at Table 7.

Here, the number of the demonstrative determiner agrees with the nondeferred referent (the pancakes) and not the literal one, again suggesting that the transfer is one of reference and not sense. Nunberg does concede that the felicity of examples involving demonstratives depends on 'specific principles of English morphosyntax' (1995:115). Whatever these principles turn out to be, the number facts do not, in fact, uniformly support Nunberg's arguments against reference transfer.

Finally, note that in the case of deferred equatives, plural demonstratives are also possible.

(18) A: Who's responsible for delivering which sandwiches?

B: I'm the sandwiches on the table. And you're those sandwiches that John put in the refrigerator, remember?

However, in this case (unlike 17), I am arguing that the postverbal NP undergoes no transfer of sense OR reference, but retains simply its literal interpretation (see below).

3.2. REFERENCE TO THE (NON)DEFERRED REFERENT. Another argument often presented in discussions of deferred reference is the alleged unavailability of the NP that forms the basis for the transfer to serve as an antecedent for subsequent anaphora. Recall that Nunberg does concede the existence of examples like 4, repeated in 19, in which the felicity of the pronominal reference might suggest that transfer applies to the full NP (the ham sandwich), rather than just the common noun (ham sandwich).

(19) I am the ham sandwich and I'd like it right now. [=4]

About this, Nunberg (1995:129ff.) says:

I don't find this an odd thing to say, but I don't think this means that the referent of the NP the ham sandwich in [19] is itself the antecedent of the subsequent pronoun. Rather, we should think of this token of $i t$ as a pronoun of laziness, analogous to the anaphors in [20a-c]:

(20) a. They enjoy eating rabbit, when there are any to be found. [Nunberg 1995, n. 13, ex. (ii)]

b. I don't speak Italian, but I'd love to go there. [Nunberg 1995, n. 13, ex. (iii)]

c. You'd better put on some mosquito repellent, just in case there are any around. [Nunberg 1995, n. 13, ex. (iv)]

In each of these sentences, a pronoun is used to refer to an entity that is semantically or materially connected to the referent of an expression in a previous clause-as rabbits to rabbit meat, Italy to Italian, mosquitoes to mosquito repellent. This phenomenon is well known, as are the constraints on this sort of usage. And [19] permits the same kind of analysis: when we use the ham sandwich to identify a person who has ordered a ham sandwich, we introduce a ham sandwich into the discourse context that is available for pronominal reference.

Thus, for Nunberg, reference to the nondeferred referent is possible only via a PRONOUN OF LAZINESS (Geach 1962, Partee 1978), that is, a pronoun that occurs as a type of syntactic substitution device to avoid repetition of its antecedent. As further support for this argument, Nunberg (1995) argues that, unlike genuinely anaphoric pronouns, pronouns of laziness disallow cataphora, as seen in 21.

(21) a. If ever you get there, you'll find Italy a lovely country. (Nunberg 1995, n. 13 , ex. (v))

b. ?If ever you get there, you'll find Italian surprisingly easy to learn. (Nunberg 1995, n. 13, ex. (vi); judgment in the original) 
This argument raises a number of issues about reference and anaphora, and it is to those issues that I now turn.

Pronouns of LAZINESS AND OUTBOUnd ANAPHORA. First, I agree with Nunberg that, when the ham sandwich is used to refer to its orderer, a ham sandwich has been introduced into the discourse model; I disagree, however, that subsequent reference to the sandwich is via a pronoun of laziness. Nunberg is arguing for two distinct sources for discourse referents: those evoked directly by referring expressions and those supplied indirectly via some kind of pragmatic inference. Interestingly, exactly the same argument was made to account for the alleged ungrammaticality of reference to entities evoked by word-internal elements, as illustrated in 22 .

(22) \#John is a truck-driver but doesn't live in it.

cf. John drives a truck but doesn't live in it.

However, as Ward, Sproat, and McKoon (1991) have shown in their work on so-called anaphoric islands, reference to entities evoked by compound-internal elements (i.e. what Postal (1969) termed OUTBOUND ANAPHORA) is fully grammatical and subject only to pragmatic - and not morphosyntactic-constraints. In particular, we argued that the felicity of a pronoun is sensitive to the salience of its referent in context; the morphosyntactic form of a pronoun's antecedent in discourse (if any) is but one of several factors that affect the salience of that pronoun. Thus any attempt to use the (in)felicity of a pronoun to argue definitively for one syntactic oR semantic structure over another is highly suspect. Consider the minimal pair in 23.

(23) a. John is a big Jane Fonda fan. He has every single one of her workout videos.

b. John is a big fan of Jane Fonda. He has every single one of her workout videos.

Under the (now discredited) outbound anaphora view of pronouns (Postal 1969, Lieber 1990) one would have to argue that the interpretation of the pronoun in $23 \mathrm{~b}$ is the result of a direct coreferential relation with its antecedent NP Jane Fonda, while the interpretation of the pronoun in $23 \mathrm{a}$ is the result of accessing the relevant entity in the discourse model that had been evoked by the compound-internal element. This is exactly the same distinction that Nunberg argues for with respect to sense transfer. So, in the case of 19 , repeated in 24 for convenience,

(24) a. I am the ham sandwich and I'd like it right now. [=19]

b. I am the orderer of the ham sandwich and I'd like it right now.

Nunberg would have to argue that the pronoun in $24 \mathrm{~b}$ has as its antecedent the NP the ham sandwich, but that in the case of 24a the pronoun has no linguistic antecedent but can be used to refer to the inferrable ham sandwich evoked by the NP the ham sandwich via meaning transfer. But as Ward and colleagues (1991) point out, there is in fact no basis for making such a distinction: all intersentential (unbound) anaphora can be accommodated under the same general mechanism of discourse-model reference. ${ }^{10}$

Furthermore, if we analyze the ham sandwich example as a case of meaning transfer, the resulting property would ITSELF contain the denotation of the $\mathrm{N}$ ham sandwich,

\footnotetext{
${ }^{10}$ As a referee pointed out, the reference facts are in fact neutral between an analysis based on 'genuine anaphoric pronouns' and 'pronouns of laziness' (assuming an adequate way of distinguishing between the two can be found), and one based on discourse model reference. But a theory that does not require an analysis based on pronouns of laziness (all other things being equal) is to be preferred on general grounds of theoretical parsimony.
} 
which would presumably be available in the discourse model for subsequent reference (as Nunberg himself points out). But whether that denotation is sufficiently salient to support subsequent pronominal anaphora is a separate issue and cannot be marshaled in support of sense transfer.

FELICITY OF DUAL REFERENCE TO DEFERRED/NONDEFERRED REFERENT. A crucial question in studies on deferred reference has been whether reference to the nondeferred referent is possible. Nunberg uses the (rather awkward) sentence in 19 to make his case, but this example does not provide sufficient context to license felicitous reference to the customer's order. Consider a more natural-sounding example of reference to the nondeferred entity in the same restaurant context.

(25) Hey, Shirley, the filet mignon at Table 7 says it's delicious.

In fact, it is possible to construct examples in which reference to both the deferred AND nondeferred entities within the same utterance is felicitous, as in 26 , in which the subject NP is a hearer-new indefinite and serves as the only available antecedent for the subsequent pronoun.

(26) Hey, Shirley, I've got a filet mignon at Table 7 that says it's the best steak $h e$ 's ever eaten.

Here, Nunberg would have to argue that the first pronoun (it) is a pronoun of laziness, while the second pronoun (he) is the result of meaning transfer, with the transferred meaning serving as that pronoun's antecedent. Under the discourse-model view of reference adopted here, both pronouns are interpreted in the same way, by reference to entities that have been rendered salient in the discourse model.

Fauconnier (1994) generally agrees with Nunberg in disallowing reference to the nondeferred referent. For example, he affixes '*?' to his example (reproduced in 27), calling it 'awkward'.

(27) The mushroom omelet left without paying. *?It was inedible. (Fauconnier 1994:6, ex. 10)

In a footnote, Fauconnier acknowledges the existence of sentences like 26 above with dual reference to the deferred and nondeferred referents.

(28) The mushroom omelet left without paying. He complained that it was inedible. (Fauconnier 1994:169, n. 3, ex. (i))

'Let us say only for present purposes that the target [the customer] is a foremost antecedent' (Fauconnier 1994:169, emphasis in the original). I take this to mean that, for Fauconnier, the target is more salient, or accessible, than the trigger, a position similar to that of Recanati 2003, to be discussed in $\S 4$. From this, of course, it does not follow that the trigger is not available for subsequent reference. But, in the case of other anaphoric processes, such as reflexivization and relative pronouns, Fauconnier is unequivocal: 'The trigger cannot be an antecedent for grammatical anaphoric processes’ (1994:169), which processes are taken up below in $\$ \S 3.3$ and 4.1, respectively.

CAtaphora. Under Nunberg's analysis, reference to the trigger is possible in deferred referential contexts, but only via a pronoun of laziness; reference to the trigger via a 'genuine anaphoric pronoun' is disallowed. As evidence, Nunberg argues that pronouns of laziness disallow cataphora (see 21b), and since deferred reference also disallows cataphora, it is reasoned that it, too, must involve a pronoun of laziness. However, the analogy is flawed in that cataphora is in fact possible with deferred reference. Consider the sentences in 29 , which my informants and I judge to be uniformly felicitous. 
(29) a. Fearing that it would get broken into, the $B M W$ shelled out $\$ 15$ for valet parking.

b. [valet to valet]

Because he's afraid it will get stolen, the $B M W$ always insists on parking it himself.

c. [server to server]

Right after he ordered it, the filet mignon at Table 7 decided he wanted it well-done rather than rare.

It may be true that cataphora is more difficult with deferred interpretations, but that could simply be the result of the added complexity of having to hold off on interpreting the pronoun until the reference transfer has been processed.

AsSOCIATIVE ANAPHORA. A fourth problem for Nunberg's account of meaning transfer is the existence of deferred reference with associative or 'indirect' anaphors (also known as inferrables, in the sense of Prince 1981, 1992). Consider the examples in 30.

(30) a. Look - the ham sandwich is tearing off the crust!

b. Look - the tomato soup is spitting out the croutons!

c. Look - the chocolate cake is scraping off the icing!

As is well known, there must be an anchoring referent in the discourse model (i.e. a salient sandwich, soup, and cake in 30a-c, respectively) for these inferrables to be licensed and interpreted appropriately (Clark 1977, Hawkins 1978, 1991, Prince 1981, 1992). That is, the crust that the speaker is referring to in 30a is not the crust that is plausibly associated with sandwiches in general, but rather it is the crust of the particular ham sandwich that the ham sandwich orderer has ordered. So, if the meaning of ham sandwich is transferred and there is no ham sandwich evoked in the discourse, then the felicity of the associative anaphora in 30 remains a mystery. Note that under Nunberg's analysis, we would expect the same forms that license a pronoun of laziness to license associative anaphora, but that is not what we find; consider 31.

(31) a. I speak Italian. \#The weather is great. (cf. 20b)

b. I've been to Italy. The weather is great.

As seen by the infelicity of $31 \mathrm{a}$, it is not the case that associative anaphora is generally possible wherever we would find a pronoun of laziness. Thus, an account based on meaning transfer alone cannot account for the well-formed examples of associative anaphora with deferred reference.

EVENT ANAPHORA. Finally, if meaning transfer can be based on a predicate, then we would expect there to be some evidence of the transferred predicate in the semantic representation or logical form of the relevant sentence. However, attempts to access the allegedly transferred predicate via subsequent event anaphora result in infelicity, as shown in 32 .

(32) a. \#John is the ham sandwich, although it's not clear why he did it.

(cp. John is the ham sandwich orderer, although it's not clear why he did it.)

b. \#The ham sandwich did so at 3:00. (did so $=$ ordered the ham sandwich) (cp. The ham sandwich orderer did so at 3:00. $)^{11}$

As Kehler and Ward argued (1999, 2004), event anaphors like do it and do so in 32 are 'deep' anaphors in that they are sensitive to the meaning of a semantic predicate and not to the particular morphosyntactic form that evokes the event in question. Thus,

\footnotetext{
${ }^{11}$ See Kehler \& Ward 1999, 2004 for arguments that support the felicity of such examples with do so.
} 
we would expect such anaphors to be felicitous when used to refer to the ordering event that corresponds to the putative transferred predicate in examples like 32. But even the most unconstrained of all event anaphors, do it, cannot access this predicate, suggesting that it simply isn't there. The problem for Nunberg is that the transferred meaning has to be there to license the pronoun of laziness that he claims is present in examples like 19. So the predicate seems to be there for subsequent pronominal anaphora, but it doesn't seem to be there for cases of subsequent event anaphora. Note that this paradox evaporates under the account of deferred reference that I am proposing here; since there is no transferred predicate in examples like 32 , their infelicity is predicted. Moreover, since both the deferred and nondeferred referents are available in the discourse model under such an account, the possibility of subsequent pronominal reference is predicted.

3.3. Reflexives, BOUND ANAPHORA, AND the SCOPE OF QUANTIFICATION. The last set of arguments that Nunberg offers in support of sense transfer-and against reference transfer-has to do with the scope of quantification, reflexives, and bound anaphora. First, Nunberg argues that for deferred reference with definite descriptions such as the ham sandwich, the definite article has scope over the transferred property ('ham sandwich orderer') and not the (nontransferred) common noun (ham sandwich). Consider the example in $3 b$, repeated in 33 .

(33) The ham sandwich is at Table 7. [=3b]

Thus, for Nunberg, the uniqueness presupposition, entailment, or implicature associated with definite NPs (Russell 1905, Hawkins 1978, 1991, Lewis 1979, Kadmon 1990, 2001, Roberts 2003, Gundel et al. 1993, Birner \& Ward 1994, 1998, Lambrecht 1994, Abbott 2004) holds of the transferred meaning, not the literal one. ${ }^{12}$ As Nunberg puts it, 33 'doesn't presuppose the existence of a unique ham sandwich (think of a waiter in a fast-food restaurant who is standing in front of a table piled with ham sandwiches), but does presuppose the existence of a unique ham-sandwich orderer' (1995:116). Sag (1981) made a similar point many years earlier with respect to the scope of cardinal and universal quantifiers, as in $34 \mathrm{a}-\mathrm{b}$, respectively. ${ }^{13}$

(34) a. There are five ham sandwiches sitting at Table 9. (Sag 1981, ex. 24a)

b. Every ham sandwich at that table is a woman. (Sag 1981, ex. 24b)

Thus, it seems clear that the meaning of these various quantifiers is associated with the deferred referent and not the literal one, that is, the restrictor of the quantifiers in 34 corresponds to the orderer(s) of the ham sandwich and not to the actual ham sandwich(es).

But what follows from such examples is that there is a mechanism of sense transfer, not that there is no mechanism of reference transfer. On the contrary, there are at least three reasons for thinking that transfers of reference are not only possible but also necessary to account for the full range of data. First, consider the case of NPs receiving a deferred reference interpretation with no common noun upon which to base the transfer.

(35) [pet owner to friend in veterinarian's waiting room where each pet is in a cage in front of its owner with its name clearly marked on it]

Wow-I wouldn't mind getting to know Rover over there.

Here, on the assumption that proper names have reference but no sense (Mill 1848, Kripke 1972/1980), the transfer would thus seem to be from one discourse referent (the dog) to another (the dog's owner).

\footnotetext{
${ }^{12}$ Birner and Ward (1998) argue that the uniqueness presupposition associated with definite descriptions is more accurately described in terms of INDIVIDUATION WITHIN THE DISCOURSE MODEL.

${ }^{13}$ Sag (1981:285) referred to the transfer process here as CONTEXTUALLY BASED SENSE TRANSFER.
} 
Second, in certain cases the determiner of the NP seems to agree, contra Nunberg, with the NONdeferred common noun within that NP. As shown in $\$ 3.1$, the facts surrounding number agreement and deferred reference are not entirely clear; recall, however, 17, the felicitous example cited earlier of number agreement with the nondeferred referent (repeated as 36).

(36) [customer to friend leering at pancake-eating customer in coffee shop] I wouldn't mind some quality time with those/\#that pancakes over at Table 7. $[=17]$

Here, the number of the demonstrative determiner agrees with the trigger (the pancakes) and not the target (the customer). We can account for the example straightforwardly by allowing a transfer of reference from the pancakes (pl.) to the pancake-eater (sg.).

Lastly, an account of deferred reference based solely on sense transfer would not be able to account for the felicity of the bound anaphor in 37 .

(37) Every filet mignon I've waited on tonight has said it was the best steak they had ever eaten!

Here, the NP with its nondeferred interpretation must still be present in the syntax to bind the c-commanded pronoun to allow the bound interpretation, even in a clearly deferred referential context. Thus, the binding facts show that, even though the restrictors of certain quantifiers correspond to the deferred interpretation alone, both the deferred AND nondeferred interpretations must nonetheless remain available.

Along the same lines, Nunberg provides one last argument in support of sense transfer based on reflexive anaphors. Consider 38a, originally from Fauconnier 1994, with the interpretation provided in $38 \mathrm{~b} .^{14}$

(38) a. *The mushroom omelet was eating itself with chopsticks. (cf. Nunberg 1995, ex. 22; judgment in the original)

b. $\rightarrow$ The mushroom omelet orderer was eating the actual mushroom omelet with chopsticks.

At issue for Nunberg is the lack of a deferred reference reading: Why can't 38a mean 38b: 'The orderer of the mushroom omelet was eating it with chopsticks'? The answer, according to Nunberg, is that the subject NP in 38a has undergone nominal transfer to 'the mushroom omelet orderer' (with a human referent) and is therefore no longer a possible binder for the (neuter) reflexive anaphor. Indeed, we find the reflexive anaphor in $39 \mathrm{a}$ agreeing with the transferred meaning in $39 \mathrm{~b}$.

(39) a. The mushroom omelet was thoroughly enjoying himself.

b. $\rightarrow$ The mushroom omelet orderer was thoroughly enjoying himself.

Here, the gender feature of the reflexive agrees with the deferred referent, that is, the person who ordered the omelet, not the omelet itself. If nominal transfer did not apply, Nunberg argues, the mushroom omelet would remain the neuter subject NP of 38a and 39a and, under normal binding conditions, the reflexive anaphor itself-c-commanded by and coindexed with the subject $\mathrm{NP}$ - would be required and the reflexive anaphor himself disallowed. Since, under the deferred interpretation, the neuter form is ungrammatical and the masculine form grammatical, Nunberg concludes that nominal transfer must have applied. ${ }^{15}$

\footnotetext{
${ }^{14}$ Another possible, but irrelevant, reading for 38a is the bizarre (nondeferred) interpretation that an actual omelet was literally eating itself with chopsticks.

${ }^{15}$ In Fauconnier's (1994) system, 38a is ruled out by stipulating that, in the case of the 'food-to-customer' connector, the application of the connector (yielding 'customer' from 'omelet') must precede reflexivization, but in the case of the 'author-to-book' connector, reflexivization may precede or follow the application of the connector. However, no independent evidence is provided for this kind of extrinsic rule ordering of some connectors but not others and, as explained below, there is a simpler alternative explanation for the reflexive facts.
} 
There is, however, an alternative explanation for the ill-formedness of 38a and the well-formedness of 39a: the gender feature of a reflexive anaphor agrees with the referent-deferred or nondeferred-of a c-commanding NP in its local domain (see Burzio 1992, Lidz 2001). As shown in 40, this holds whenever that NP is unspecified for gender. ${ }^{16}$

(40) a. That drag queen is very impressed with himself/herself.

b. Someone is very impressed with himself/herself.

In this way, on independent grounds, the interpretation of reflexives in general requires access to information about the referent of an expression and the same applies to the interpretation of deferred referents. No special appeal to meaning transfer is required, thus eliminating it, too, as an argument against reference transfer. ${ }^{17}$

Crucially, note that the NP with its nondeferred interpretation is still available to bind a pronoun, even in clearly deferred referential contexts.

(41) a. The filet mignon complained that it was overcooked and the poached salmon did too.

b. $\rightarrow \ldots$ and the poached salmon complained that the poached salmon was overcooked.

c. The orderer of the filet mignon complained that it was overcooked and the poached salmon did too.

In 41a, the NP the filet mignon can be used to refer to the orderer of the filet mignon, and yet this NP can nonetheless also bind a c-commanded pronoun in the next clause, suggesting that the NP (in its nondeferred interpretation) is present for the purposes of bound anaphora. That this is an instance of variable binding and not simply coreference is illustrated by the possibility of the 'sloppy identity' reading in the second (elided) clause of 41a, as shown in 41b: ' . . the orderer of the poached salmon complained that the poached salmon was overcooked'. Moreover, as one would expect, the same NP in 41c is not able to serve as a binder for the pronoun since, unlike the NP in 41a, it does not c-command the pronoun. Although the pronoun in the main clause can be used to refer to the nondeferred referent, this is not a case of variable binding. In this example, ellipsis licenses only the strict interpretation; that is, the sloppy reading in $41 \mathrm{~b}$ is unavailable, confirming that the pronoun in 41c is not bound. Taken together, these facts suggest that for at least some deferred nonequatives, the NP corresponding to the literal referent remains present in the syntax with its nondeferred interpretation.

4. An alternative account. In light of these problems with previous accounts of deferred reference based solely on meaning transfer, I believe an alternative account merits consideration. I agree with Fauconnier (1994) and Nunberg (1995) that the felicitous use of deferred reference requires a contextually licensed correspondence

${ }^{16}$ As Tonia Bleam notes (p.c.), this principle does not apply to antecedent NPs that are syntactically marked for number and gender features, as in (i).

(i) a. Our female cat is so smart it recognizes itself/*herself in the mirror.

b. Our female cat is so smart she recognizes *itself/herself in the mirror.

In (ia), the reflexive is forced to agree with the syntactic gender feature present in the subject pronoun, despite the real world gender of the referent.

${ }^{17}$ Joseph (1979) observes an analogous situation with respect to the number feature for the head of reflexives (i.e. -self/-selves). Consider the example of 'nursely we' in (i).

(i) We seem a bit displeased with ourself/*ourselves, don't we? (Joseph 1979, ex. 9)

Here, the possessive part of the reflexive (our) must agree with the number of the subject NP (plural), while the head of the reflexive (-self) agrees with the number of the intended referent (singular). 
from one object to another. But I claim that such a correspondence applies to equatives and nonequatives differently. In the case of equatives like 2a, the pragmatic mapping between set members is explicitly encoded by the two NPs of the equative construction and no reference transfer is involved. For nonequatives as in 1a, the mapping is implicit and only one of the mapped set members is explicitly evoked in the discourse, yet as a result of transfer, both set members may be available for subsequent anaphoric reference under the right pragmatic conditions. That is, the referential availability of both mapped set members is, in the case of equatives, the result of explicit evocation, while in the case of nonequatives, it is the result of either sense or reference transfer.

I am assuming here a view of reference that makes crucial use of the notion of DISCOURSE MODEL (Sidner 1979, Webber 1979, Grosz \& Sidner 1986). Under this view, reference is seen as an interactive, dynamic process between speakers and hearers-specifically, the use of a linguistic expression to induce a hearer to access or create some entity in his or her mental model of the discourse. A discourse entity represents the referent of a linguistic expression, that is, the actual individual (or event, property, relation, situation, and so on) that the speaker has in mind and is saying something about. Within philosophy and formal semantics, the traditional view has been that reference is a direct relationship between linguistic expressions and the objects in the real world that they denote. The discourse-model approach, however, takes a different perspective, viewing this relation as mediated through the (assumed) mutual beliefs of the participants. Under this view, the form of referring expression depends on the assumed INFORMATION STATUS of the referent, which in turn depends on the assumptions that a speaker makes regarding the hearer's knowledge store as well as what the hearer is attending to in a given discourse context (Ariel 1990, Gundel et al. 1993, Prince 1992). Entities that are more salient, or accessible, are more available for subsequent reference. No single factor accounts for the accessibility of discourse entities, but among the factors that determine salience are recency of mention, contrast, topicality, argument position, and morphosyntactic form of the antecedent (if any). (See Ward et al. 1991, Kehler \& Ward 2004.)

In a similar vein, Recanati (2003) argues for an account of deferred reference in terms of the dual notions of activation and accessibility:

\footnotetext{
When the words the ham sandwich are uttered, we may ... suppose that the representation of the ham sandwich is more active than the 'derived' representation of the ham sandwich orderer because it is linguistically encoded and has some form of priority over the ham sandwich orderer (derived value). [This] initial ranking is reversed when further linguistic material comes into play. After the predicate in the sentence The ham sandwich has left without paying has been processed, the ham sandwich is no longer a more accessible candidate than the ham sandwich orderer - the order of accessibility is reversed ... The predicate has left without paying demands a person as argument; this raises the accessibility of all candidates who are (represented as) persons. In this way the representation of the ham sandwich orderer gains some extra activation which makes him more accessible than the ham sandwich, after the predicate has been processed.
}

Under this view, вотн representations (the trigger and the target, in Fauconnier's terms) are available in the discourse model; they differ only in terms of their relative accessibility as determined by the discourse context. One of the factors that affects accessibility is the salience of the correspondence between trigger and target.

To illustrate, consider again examples 1a and 35, repeated below as 42a and 42b, respectively.

(42) a. The ham sandwich is at Table 7. [=1a]

b. Wow-I wouldn't mind getting to know Rover over there. $[=35]$ 
For such nonequatives as these, the relevant correspondence is implicit. The server who utters $42 \mathrm{a}$ asserts not that his customer has ordered the ham sandwich, but that she is at Table 7. His use of deferred reference presupposes that his hearer can access the relevant correspondence between customers and orders upon which to base the transfer. In certain cases of deferred reference the transfer operation applies to the denotation of the bare nominal as in 42a. In other cases involving correspondences that are highly context-specific (or 'extralexical', Nunberg 1995), as in 42b, it applies to the referent of the linguistic expression. ${ }^{18}$ That is, both (pragmatic) transfers of reference and (semantic) transfers of sense are possible; for both types of transfer, however, the trigger and target are available in the discourse model for subsequent reference, given sufficient accessibility. ${ }^{19}$

One interesting constraint on the transfer operation is that the trigger itself must be SEMANTICALLY COHERENT: NPs that simultaneously denote the deferred and nondeferred referent are incoherent and thus fail to license felicitous deferred reference.

(43) a. ?A tall, bearded ham sandwich left me a big tip.

b. ?The short, fat Volvo paid with a credit card.

c. ?An obnoxious ham sandwich has been hitting on me.

Here, the deferred reference interpretation is difficult to access due to the lack of a coherent discourse entity corresponding to the subject NP in these examples. The NP in 43a, for example, does not lend itself to the construction of a single, coherent entity given the real-world incompatibility of the adjectives tall and bearded with ham sandwich. Thus, transfer in this case is inhibited, as the listener must simultaneously construct two discourse entities (a ham sandwich and the person who ordered it) out of a single NP. ${ }^{20}$ But once a coherent entity has been established in the prior discourse, then additional modification of that entity is fine, as in 44 .

(44) a. [bartender to bartender]

Boy, have I had a rough day today! This guy I'd never seen before-a gin and tonic — started to get unruly during happy hour. He started harassing some of the customers. Then this margarita at Table 7 started mouthing off. Finally, I had to ask the obnoxious gin and tonic to leave.

b. Hey, Bob. That tall gin and tonic you like so much is back.

Once the orderer of the gin and tonic has been established, or assumed to be known to the addressee, subsequent transfer to that entity with additional modification is possible. The problem arises when a speaker attempts to use a single NP to introduce both a deferred and nondeferred referent simultaneously without appropriate contextualization. ${ }^{21}$

\footnotetext{
${ }^{18}$ Following Nunberg, an EXTRALEXICAL use is one that is accounted for exclusively by pragmatic principles, with no need for any lexical specification.

${ }^{19}$ See Sag 1981 for a number of proposals on how such a mapping might be formalized. Sag himself, however, ends up arguing against the notion of reference transfer and in favor of sense transfer, corresponding to (and subject to the same problems as) Nunberg's notion of predicate/nominal transfer.

${ }^{20}$ As an anonymous referee points out, such dual reference is not in principle impossible; it just requires the appropriate licensing context for its felicity.

${ }^{21}$ Note that the infelicity of the examples in 43 cannot be accounted for by allowing transfer on the common noun along with its modifiers; the following examples show that modifiers may have scope over the nondeferred referent as well, as in (i).
}

(i) a. The tattered plaid shirt left me a big tip.

b. The burnt steak wants a refund.

c. The well-done hash browns needs another OJ.

I thank Betty Birner for the latter two examples. 
In the case of deferred equatives, a rather different situation obtains. First, note that for canonical equatives, two distinct NPs are used to refer to the same discourse entity, as when a speaker uses 45 to assert that Chris and the guy in question are the same individual.

(45) Chris is the guy I was telling you about.

In deferred equatives, though, the two NPs are not themselves coreferential; rather, the equative encodes the mapping between members of distinct sets of discourse entities. That is, the referential mapping that is characteristic of extralexical deferred reference in general is explicitly realized in a deferred equative. A diner could, for example, use the equative in $2 \mathrm{a}$ (repeated below as $46 \mathrm{a}$ ) to assert that she is the person who ordered the pad thai, while at the same time presupposing that there exists a salient mapping between restaurant customers (set 1) and their orders (set 2).

(46) a. I'm the pad thai. [=2a]

b. I MAP ONTO the pad thai.

Crucially for deferred equatives, both of the mapped set members- 'I' and 'the pad thai' in the above example-are explicitly represented, with the copula interpreted as linking the two set members rather than literally equating them, as informally represented in 46b. This extension or COERCION of copular meaning from 'be' to 'map onto' is similar to Nunberg's notion of predicate transfer, but it is much more constrained. First, it applies only to the copula be of equatives (for Nunberg, any verb-in an equative or not-can undergo predicate transfer); second, it applies only to the verb and not to its arguments. ${ }^{22}$ Under this analysis, then, the deferred equative in $46 \mathrm{a}$ is, unlike the deferred nonequative in $42 \mathrm{a}$, literally true (assuming a mapping relation holds between the referents of the two NPs of the equative).

Now let's compare the equative in $46 \mathrm{a}$ with the nonequative in $42 \mathrm{a}$, in which the extralexical mapping between customers and orders is left implicit. In fact, what distinguishes deferred equatives from deferred nonequatives is precisely the explicitness of the encoding of the mapping operation, which we can represent by means of an open proposition (OP). ${ }^{23}$

\footnotetext{
22 This analysis of copular coercion accounts for the fact that deferred equatives are not straightforwardly translatable into other languages with copular equative constructions, as the meaning of the copula is well known to be highly idiosyncratic and to vary widely across languages. My Italian informants, for example, tell me that the deferred equative in (i) is very awkward, if not impossible.
}

(i) \#Sono il panino. $\rightarrow$ 'I am the orderer of the sandwich.'

I.am the sandwich

${ }^{23}$ Note that, under this analysis, equatives such as (i) are not strictly speaking deferred equatives, although they do have a deferred interpretation.

(i) The ham sandwich is my brother-in-law. $\rightarrow$ 'The ham sandwich orderer is my brother-in-law.' Here, the context does NOт license a salient mapping between the set of which the ham sandwich is a member, for example, $\{$ lunch orders\}, and the set of which my next-door neighbor is a member, for example, \{people I know\}; thus, no coercion of $b e$ is warranted and, consequently, no salient OP of the form ' $\mathrm{X}$ MAPS ONTO $\mathrm{Y}^{\prime}$ is required. The deferred interpretation here is the result of reference transfer applying to the subject NP: from the sandwich to the person who ordered it. In this way, (i), despite the equative syntax, is a gardenvariety example of reference transfer. This difference between OP-based and non-OP-based equatives is actually pragmatically realized in Japanese. As noted in Kuno 1973, OP deferred equatives occur regularly, as exemplified in (ii).

(ii) Boku wa unagi desu. $\rightarrow$ 'I am the orderer of the eel.'

I topic eel be

However, as Yoshiko Matsumoto (p.c.) observes, the corresponding non-OP deferred equative in Japanese (corresponding to the English (i) above) is not felicitous, as in (iii).

(iii) \#Unagi wa boku no giri no otooto desu.

eel topic I GEN in-law GEN brother be

$\rightarrow$ 'The eel orderer is my brother-in-law.'

Thus, there is some crosslinguistic evidence that OP-based deferred equatives constitute a distinct pragmatic construction. 
4.1. Deferred equatives And open Propositions. An OP is a proposition with one or more variables or underspecified elements, corresponding to that aspect of information structure that constitutes backgrounded or presupposed information. Consider the examples of OP-sensitive constructions in 47 and 48.

(47) a. I plan to discuss several topics. What I'll discuss first is the notion of political correctness.

b. OP: I'LL DISCUSS X FIRST.

c. FOCUS: the notion of political correctness

(48) a. I'm not really into sports. Baseball I like, but more for the scene at Wrigley Field than the actual game.

b. OP: I HAVE DISPOSITION X TOWARDS \{SPORTS\}.

c. FOCUS: like

In $47 \mathrm{a}$, the first sentence (I plan to discuss several topics) makes accessible the proposition that I will discuss some topic first. Thus, the open proposition 'I'll discuss X first' is salient, in which $\mathrm{X}$ is a variable ranging over the set \{topics\}. It is the salience of this OP that licenses the use of the wH-cleft in the second sentence; the expectation that the speaker will discuss some topic first renders the use of the cleft felicitous. The instantiation of the variable selected from this set-here, the notion of political correctness - constitutes the focus of the utterance and is realized prosodically with a pitch accent. This packaging of information into an open proposition and a focus corresponds closely to the focus/presupposition (or focus/focus frame) distinction of Chomsky 1971, Jackendoff 1972, Rochemont 1986, Vallduví 1992, Lambrecht 1994, and Gundel \& Fretheim 2004.

Similarly, the first sentence in 48 a evokes the notion that I have certain likes and dislikes regarding sports. The OP 'I HAVE DISPOSITION X TOWARDS SPORTS' is thus salient and licenses the preposing in the second sentence (Baseball I like). The instantiation of the variable here is the focused element like. Without a salient OP, the preposing would be infelicitous.

(49) a. My father-in-law is visiting this weekend. \#Baseball I like, so at least we'll have something to talk about.

b. My father-in-law is visiting this weekend. I like baseball, so at least we'll have something to talk about.

In these examples, the initial sentence does not make salient the notion that the speaker has various likes and dislikes toward different sports, and therefore the preposed variant is infelicitous, as in 49a. The nonpreposed variant in 49b, however, is felicitous, since the use of canonical word order does not require the presence of a salient OP. (For further discussion of OPs and the constructions that are sensitive to them, see Prince 1986, Ward 1988, Birner \& Ward 1998, and Birner et al. 2001.)

In the case of deferred equatives, the relevant OP contains two variables, corresponding to the two sets from which the instantiations of these variables are drawn. Consider $2 \mathrm{a}$, repeated below as $50 \mathrm{a}$.

(50) a. I'm the pad thai.

b. OP: $\mathrm{X}$ MAPS ONTO $\mathrm{Y}$ (where $\mathrm{X}$ is a member of the set \{customers\} and $\mathrm{Y}$ is a member of the set $\{$ orders\}).

c. FOCI: I, the pad thai 
The OP corresponding to 50a is formed in the usual way by replacing the two foci ( $I$, the pad thai) with variables, as in 50b. The instantiation of the variables must be drawn from the two sets involved in the mapping. For this example, one might gloss the instantiation informally as: 'I, a member of the set of customers, correspond to the pad thai, a member of the set of orders.' What makes the utterance in 50a deferred is not a transfer of sense or reference from either of the equative NPs; rather, it is the coercion of be to map onto as represented in the OP. In this way, there is no need to invoke any kind of predicate, nominal, or reference transfer mechanism for deferred equatives.

In fact, it is this coercion of the copula's meaning that requires the presence of a salient OP. Note that without the OP in $50 \mathrm{~b}$ being salient, the deferred equative is infelicitous, as seen in 51.

(51) A: How was your meal?

B: Good. \#I was the pad thai.

Here, the OP in 50b-that various customers correspond to orderers of various dishes-is not salient, and the deferred equative is therefore infelicitous. In contrast, note that the corresponding nondeferred reference is felicitous, as in 52 .

(52) A: How was your meal?

B: Good. I had the pad thai.

From this we can conclude that the infelicity observed in 51 is not the result of one's answering the question 'How was your meal?' with a description of what one ate. Nor is it the result of referring to one's lunch order with a definite article, as long as that order is uniquely identifiable in context. ${ }^{24}$ Rather, the infelicity of the deferred equative in 51 can be attributed to the absence of a contextually salient double-variable OP. It is crucial that there be two variables; as 53 shows, a single-variable OP is insufficient to guarantee felicity.

(53) A: Sorry you had to have lunch all by yourself. What did you have?

B: \#I was the pad thai. (cf. I had the pad thai.)

Here, the single-variable OP 'I HAD X FOR LUNCH' is insufficient to license the deferred reference. Note that nondeferred equatives, illustrated in 54 , are not subject to this constraint.

(54) a. I think that guy over there is my next-door neighbor.

b. Hello. I'm the chair of the linguistics department. I'm calling to see if ...

c. George Bush is the president of the United States.

None of these equatives requires that any particular OP be salient to ensure felicity.

A crucial consequence of the difference between deferred equatives and nonequatives is that in the case of equatives, both of the NPs can retain their literal interpretation even under a deferred interpretation. For example, in the case of I'm the pad thai, only the copula undergoes a transfer of meaning; the referent of the post-copular NP is the

\footnotetext{
${ }^{24}$ For a discussion of the pragmatic constraints on the definite article, see Kadmon 1990, Hawkins 1991, Gundel et al. 1993, Birner \& Ward 1994, Lambrecht 1994, Roberts 2003, and Abbott 2004.
} 
actual pad thai. ${ }^{25}$ This difference can be teased out with the addition of a relative clause, as in 55 and $56 .^{26}$

(55) a. \#John is the pad thai, who drives a Rolls Royce.

b. John is the pad thai, which looks delicious.

c. John is talking to the pad thai, who drives a Rolls Royce.

(56) a. \#The pad thai, who drives a Rolls Royce, is John.

b. The pad thai, which looks delicious, is John.

c. The pad thai, who drives a Rolls Royce, is talking to John.

In 55a, the intended interpretation - that John, who ordered the pad thai, drives a Rolls Royce-is unavailable, suggesting that the referent of the predicate NP is the actual pad thai and not John. The felicity of the relative clause in 55b-with the pad thai as head of the relative clause-confirms this analysis. In the nonequative in 55c, in contrast, the intended interpretation - that the person who ordered the pad thai drives a Rolls Royce-is well formed, suggesting that the referent of the relevant NP in the nonequative sentence is not the pad thai, but the one who ordered it. The same contrast between equatives and nonequatives applies to NPs in subject position, as seen in the corresponding examples in $56 .{ }^{27}$

The same pattern emerges from wh-questions with deferred interpretations, as exemplified in 57.

(57) a. Let's see ... You're what, the pad thai or the nam sod?

b. \#Let's see ... You're who, the pad thai or the nam sod?

(58) a. \#Tell me honestly, what do you like more, the pad thai or the nam sod?

b. Tell me honestly, who do you like more, the pad thai or the nam sod?

Again, the preferred form for the wH-question corresponding to the equative in 57 is what, showing agreement with the nonhuman (and nondeferred) referent. Conversely, the preferred form for the wH-question corresponding to the nonequative in 58 is who, showing agreement with the [+ HUMAN] feature of the deferred referent. The same contrast surfaces with clefts, as shown in 59 and 60 .

\footnotetext{
${ }^{25}$ It is possible for a single equative to draw upon multiple mappings, as with the example in n. 6, The Rolls Royce is the ham sandwich. In this example there are in fact two distinct mappings: a mapping between the cars and customers and another between customers and their orders. The equative encodes only the latter mapping, however.

${ }^{26}$ Fauconnier (1994) uses nonrestrictive relative clauses (with nonequatives) to support his claim that the nondeferred referent is unavailable for subsequent anaphoric reference.

(i) *The omelet, which was too spicy, left in a hurry. (Fauconnier 1994, ex. 26; judgment in the original)

(ii) Plato, who was a great man, is on the top shelf. (Fauconnier 1994, ex. 25)

To account for the alleged ungrammaticality of (i), Fauconnier claims that the function from food to customers is CLOSED, that is, it does not permit reference to the trigger. In contrast, the function from authors to books, illustrated in (ii), is claimed to be OPEN in that it does permit reference to either the trigger or target. However, as the reader has already seen, reference to the nondeferred NP-both with anaphoric pronouns and nonrestrictive relatives-is grammatical and-depending on context-felicitous, suggesting that no function is 'closed' in this sense (cf. exx. 25 and 55b).

${ }^{27}$ It has been suggested (by a referee) that the infelicity of 55a may be the result of a general prohibition on nonrestrictive relatives modifying the postverbal NP of equatives. But the felicity of the examples below suggests that such an account cannot be maintained.
}

(i) John is my husband, who I love even more than my last one.

(ii) He's the neighbor's kid, who just got arrested for drunk driving.

(iii) John is my best friend, who lives on Elm Street. 
(59) a. What I am is the pad thai, not the nam sod.

b. \#Who I am is the pad thai, not the nam sod.

(60) a. Who you should be checking out is the pad thai, not the nam sod.

b. \#What you should be checking out is the pad thai, not the nam sod.

The deferred equative cleft in 59a, while admittedly awkward, is significantly more felicitous with the relative pronoun for nonhumans than the corresponding cleft in $59 \mathrm{~b}$ with the relative pronoun for humans, again suggesting that the referent of the pad thai is the actual dish and not the orderer. However, with the deferred nonequative clefts in 60 , the judgments are reversed, suggesting that a transfer of reference to the orderer has indeed applied.

Finally, there is evidence that the definite article of the postverbal NP of a deferred equative is associated with the nontransferred meaning. Consider the examples in 61-63, if uttered in a context in which a number of reporters from every major newspaper are present at a national press conference. ${ }^{28}$

(61) a. John's the Washington Post. $\rightarrow$ 'John's a reporter for the Washington Post.'

b. \#John's a Washington Post.

(62) a. John's the morning paper. $\rightarrow$ 'John's a reporter for the morning paper.'

b. \#John's a morning paper.

(63) a. John's Newsweek. $\rightarrow$ 'John's a reporter for Newsweek.'

b. \#John's a Newsweek.

In 61a, given the existence of multiple Washington Post reporters at the press conference, the definite article cannot be associated with a uniquely identifiable reporter. Rather, the relevant correspondence is between John and the uniquely identifiable newspaper. ${ }^{29}$ An account based on nominal transfer, in which the definite article would have scope over the transferred meaning, cannot account for the infelicity of $61 \mathrm{~b}$. Similarly, 62a could be uttered felicitously in a context in which a particular city had only a single morning paper. That is, the definite article-indicating unique identifiability - applies to the (nondeferred) newspaper, of which there is one, and not to the (deferred) reporter, of which there are several. The infelicity of the indefinite article in $62 \mathrm{~b}$ bears out this analysis. Along the same lines, nominal transfer would incorrectly predict the felicity of $63 \mathrm{~b}$.

Thus, for deferred equatives, an account based on mapping with a concomitant shift in copula meaning correctly predicts that the copular NPs are interpreted literally and that their (nondeferred) referents are available in the discourse model for subsequent reference. Of course, it is possible for one of the copular NPs to itself undergo a sense transfer while still participating in a pragmatic mapping. Consider again $2 \mathrm{c}$, repeated in 64 for convenience.

(64) [physician assigning interns to patients]

You and you are shortness of breath. You and you take vertigo. $[=2 c]$

This utterance was produced in a context in which the attending physician of an emergency room was running through a list of symptoms and assigning each to a particular intern. The equative serves to encode the pragmatically salient mapping between interns and symptoms. However, the post-copular NP shortness of breath, describing a patient's

\footnotetext{
${ }^{28}$ I am grateful to a referee for bringing these examples to my attention.

${ }^{29}$ Indeed, in this context one could say (truthfully) of John and Mary (both of whom work for the Post) that John is the Washington Post and that Mary is the Washington Post, too.
} 
symptom, itself undergoes a sense transfer from symptom to patient. Thus, the equative maps an intern to a given symptom, the latter undergoing a sense transfer to the corresponding patient displaying that particular symptom. ${ }^{30}$

4.2. Kind-InTERnAL vs. KIND-EXTERnAL DEFERRED REFERENCE. Within the class of deferred equatives, an important distinction is whether the pragmatic mapping holds between sets of like or unlike kinds, as illustrated in 65 and 66, respectively.

(65) a. [parent to day care employee]

I'm the cowboy. $\rightarrow$ 'I'm the parent of (the boy dressed as) the cowboy.'

b. [family members discussing Secret Santa assignments]

Who'd you get? I'm Anne. $\rightarrow$ 'I'm the family member assigned to Anne.'

(66) a. [valet to valet]

He's the red Toyota. $\rightarrow$ 'He's the driver of the red Toyota.'

b. [neighbor to neighbor at community association meeting]

I'm the brick two-flat on Eddy. $\rightarrow$ 'I'm the owner of the brick two-flat on Eddy.'

The mapping in $65 \mathrm{a}$ - between parents and cowboys - is of a type that I call KINDINTERNAL. That is, both NPs denote humans and, more relevantly, it is plausible for the copular to be interpreted as a canonical (nondeferred) equative. Since parents (including the speaker in 65a) can, in principle, be cowboys, the mapping here is kind-internal. The mapping in $66 \mathrm{a}$ - between drivers and their cars-is what I call KIND-EXTERNAL. One NP denotes a human, the other an artifact. And since it is not plausible for a driver to be an actual car, the equative in 66a can receive only a deferred interpretation.

Although both kind-internal and kind-external deferred reference is possible with equatives, the kind-external variety is nonetheless judged by informants to be significantly more felicitous in 'out-of-the-blue' contexts. Consider the contrast in 67.

(67) a. Mr. Sampieri is the martini. $\rightarrow$ 'Mr. Sampieri is the person drinking the martini.'

b. \#Mr. Sampieri is the cowboy. $\rightarrow$ 'Mr. Sampieri is the father of the (boy dressed as the) cowboy.'

The reason for the difference in felicity is clear: kind-internal equatives require greater contextualization (and arguably greater processing) than kind-external equatives to override the literal interpretation (when plausible) and to trigger the deferred interpretation. In the absence of such a context, the deferred interpretation is less accessible and kind-internal equatives are correspondingly disfavored.

The preference for kind-externals is not unique to equatives; it applies to nonequatives as well, as shown in 68 .

(68) a. The martini is very cute. $\rightarrow$ 'The person who is drinking the martini is very cute.'

b. \#The Italian is very cute. $\rightarrow$ 'The person who is kissing the Italian is very cute.'

\footnotetext{
${ }^{30}$ A referee provided a very nice minimal pair contrasting the difference between pragmatic mapping and sense transfer.

(i) Tuesday is Merle Haggard.

(ii) Tuesday is the Merle Haggard.

A ticket agent could use the deferred equative in (i) to map days of the week onto performers; the proper name here retains its literal interpretation. In (ii), by contrast, the post-copular NP undergoes a meaning transfer from performer to concert.
} 
Here, informants again prefer-even more strongly than in the case of equatives-the kind-external deferred reference in $68 \mathrm{a}$ to the kind-internal variant in $68 \mathrm{~b} .{ }^{31} \mathrm{We}$ can attribute this general preference for kind-external equatives to a variant of the Gricean 'Avoid Ambiguity' submaxim (Grice 1975): A hearer will generally opt for a less effortful nondeferred interpretation - if it is plausible-over a deferred one. Since Mr. Sampieri could plausibly be a cowboy, but not a martini, $67 \mathrm{a}$ is preferred over $67 \mathrm{~b}$. Similarly in the case of nonequatives, since martinis can't be cute, but Italians certainly can be, 68 a induces a deferred interpretation more readily than $68 \mathrm{~b}$, which has a plausible nondeferred interpretation. ${ }^{32}$

However, when we compare equatives with nonequatives, a different situation obtains. First, compare the two kind-internal utterances in 69.

(69) a. Mr. Sampieri is the cowboy. $\rightarrow$ 'Mr. Sampieri is the father of the (boy dressed as the) cowboy.'

b. \#The Italian is very cute. $\rightarrow$ 'The person who is kissing the Italian is very cute.'

When given a forced choice between a kind-internal equative 69a and a kind-internal nonequative $69 \mathrm{~b}$ in a null context with the interpretations provided, informants consistently prefer the former. Now consider the kind-external utterances in 70 .

(70) a. Mr. Sampieri is the martini. $\rightarrow$ 'Mr. Sampieri is the person drinking the martini.'

b. The martini is very cute. $\rightarrow$ 'The person who is drinking the martini is very cute.'

Informants did not show any preference for the kind-external equative in 70a over its nonequative counterpart in $70 \mathrm{~b}$ - both were judged equally felicitous. Thus, use of an equative - a ready-made double-focus construction-seems to facilitate kind-internal deferred reference, whereas kind-external deferred reference does not appear to require such facilitation.

When informants were asked to provide possible contexts for kind-internal deferred reference, they produced in every instance ones that drew upon a double-variable OP. One informant, for example, suggested the following as a context for 68b: 'Some sort of kissing show, where $\mathrm{X}$ is kissing an African, $\mathrm{Y}$ is kissing a Pole, $\mathrm{Z}$ is kissing a native American, A is kissing an Italian, B is kissing a Jew, $\mathrm{C}$ is kissing a Norwegian, etc.' Another informant suggested this slightly more imaginative context: 'This would only be possible (and very marginal even under these conditions) if there is a set of European soccer players, each one from a different country, being kissed by aspiring spokesmodels trying out for a minor role in a commercial, in which a beautiful woman wanders up to a set of famous footballers and kisses them. The quality of the kissing and the cuteness of the kissers is being evaluated.' In any event, it would appear that

\footnotetext{
${ }^{31}$ In fact, some informants went so far as to claim that kind-internal nonequatives were ungrammatical.

${ }^{32}$ As a referee pointed out, another relevant factor, no doubt, is the degree of complexity associated with the inference required to get from the NP to the speaker's intended (and deferred) referent. That is, even 67 a will become hard to interpret if the intended interpretation is, for example, 'the father of the boy who spilled the martini' rather than 'the drinker of the martini'. Again, the degree to which the mapping is transparent is sensitive to the perceived frequency of the encoded mapping: people stand in a drinking relation to martinis more frequently (stereotypically?) than they do in a spilling relation. (See Nunberg's (1995) criterion of 'noteworthiness' in this regard.)
} 
when a nondeferred interpretation is plausible, the presence of a context that licenses a double-variable OP can induce a deferred interpretation, and the equative construction greatly facilitates this interpretation.

The relative placement of the two NPs in a deferred equative is also relevant. The subject NP is privileged in the sense that it constitutes the anchor (in the sense of Birner \& Ward 1998) that forms the basis for the reference mapping. That is, it represents the referent to which the other entity is mapped. It is relatively easy to imagine contexts in which Mr. Sampieri is the cowboy means 'Mr. Sampieri is related to the cowboy', but more difficult to imagine contexts for the reverse order: The cowboy is Mr. Sampieri. One possible context would be a list of student performers, each of whom has been assigned to a parent to escort him/her around campus. In this situation, the cowboy is the anchoring NP with Mr. Sampieri being mapped to its discourse model referent.

5. Survey. To investigate the proposed constraints on deferred equatives, Ward and Tilsen (2002) conducted an experiment in which subjects were presented with a series of twenty-eight scenarios and asked to rate the felicity of a deferred equative associated with each scenario on a five-point scale. Subjects were Northwestern University graduate students in linguistics and undergraduates taking linguistics courses who participated in the experiment as part of a course requirement. The data from two nonnative speakers were excluded from the final analysis. To vary the order of presentation across subjects, we blocked the twenty-eight scenarios in four groups of seven. The instructions are provided in Appendix A.

Pooling subjects, the mean ratings of the scenarios ranged from a low of 1.46 to a high of 4.26. As expected, the mean score for kind-external scenarios (3.32) was significantly higher than the mean score for kind-internal scenarios (2.47). Indeed, for 32 of the 35 subjects, their mean kind-external scores were greater than their mean kind-internal scores, as illustrated in Appendix B. The scenario judged to be most felicitous-a variant of Nunberg's classic ham sandwich example-was kind-external; it is provided in 71 .

(71) Jim is at his favorite restaurant with a group of friends. The restaurant is very busy and it's taking forever for their food to arrive. Finally, the waiter brings out the orders, apologizing profusely. By now, he has completely forgotten what everyone has ordered. He looks dazed and confused. Jim decides to help him out, saying:

$\rightarrow$ I'm the roast beef.

Among kind-internal deferred references, we found that those involving mappings between animate entities (i.e. between humans and humans, or animals and animals) were judged to be significantly more felicitous than those involving artifacts.

Interestingly, the highest scoring kind-internal scenario involved deferred reference to a newborn infant.

(72) Due to a tightening of regulations at Riverside Hospital, no observers are allowed in the delivery room. On this particular day, the number of births exceeded the hospital record before noon, so nurses were delayed in getting all the babies out to the viewing area. A group of weary parents are eagerly waiting next to the window. They have been there for hours without really speaking to one another, but once the babies are wheeled in, all the parents start pointing out their respective newborns. One parent says proudly to the person next to him:

$\rightarrow$ I'm the redhead. 
We tested a number of scenarios in which adults used deferred equatives such as I'm the cowboy, ballerina, elf, and so on to refer to children related to them. We found that, as a general rule, as the age of the child in the scenario increased, the naturalness rating decreased. Along the same lines, our informants judged deferred reference to adult children, such as I'm the cellist when uttered by a proud parent to a stranger at a symphony orchestra, to be generally infelicitous. However, in a context in which only parents of the (adult) symphony members are invited to the concert (so that it's clear that everyone in the audience is a parent of one of the musicians) the example becomes much more felicitous. What these examples show is that the younger the child in question, the more accessible — and hence more salient- the OP ' $\mathrm{X}$ IS THE PARENT $\mathrm{OF} \mathrm{Y}^{\prime}$ ' is in context. And, consequently, the more salient this OP, the more felicitous the corresponding deferred equative and associated pragmatic mapping.

6. Conclusion. The findings presented here support an account of deferred equatives based on the notion of pragmatic mapping. This mapping is explicitly encoded by the two NPs of the equative construction, neither of which undergoes a transfer of sense or reference and both of whose referents are available in the discourse model for subsequent reference. Moreover, deferred equatives require that an open proposition be salient in the discourse at the time of utterance. For nonequatives, I argued that the pragmatic mapping is implicit and that only one of the mapped set members is explicitly evoked in the discourse. For certain extralexical mappings, both set members may nonetheless be available for subsequent anaphoric reference as a result of reference transfer, subject to accessibility. It remains to be seen to what extent this account can be extended to the other deferred reference constructions.

Appendix A: Instructions to subJects

In this experiment, you will be asked to read a number of short paragraphs, each describing a situation. Following each paragraph, there is a final sentence preceded by an arrow $(\rightarrow)$. You are to judge the naturalness of this final sentence by circling a number on a scale of 1-5. A 'natural' sentence is one that you can easily imagine yourself or other native speakers of English saying in a particular situation.

Please judge only the naturalness of the sentence following the arrow (and not the entire paragraph). Here is an example paragraph:

Two flight attendants on a flight to Los Angeles are about to distribute the dinner meals. A passenger had requested a special low-sodium meal, but the flight attendants can't find the special meal request list. Fortunately, one of them remembers and says:

$\rightarrow$ Seat $39-\mathrm{B}$ is the low sodium.

\begin{tabular}{lccr} 
Very unnatural & Somewhat natural & Very natural \\
1 & 2 & 3 & 4 \\
\hline
\end{tabular}

So, if you think 'Seat 39-B is the low sodium' is a very natural thing to say in this situation, then you should circle 5. If you think it is a very unnatural thing to say, then you should circle 1 . If you think the sentence is somewhat natural-sounding, circle 3 , and so on. 


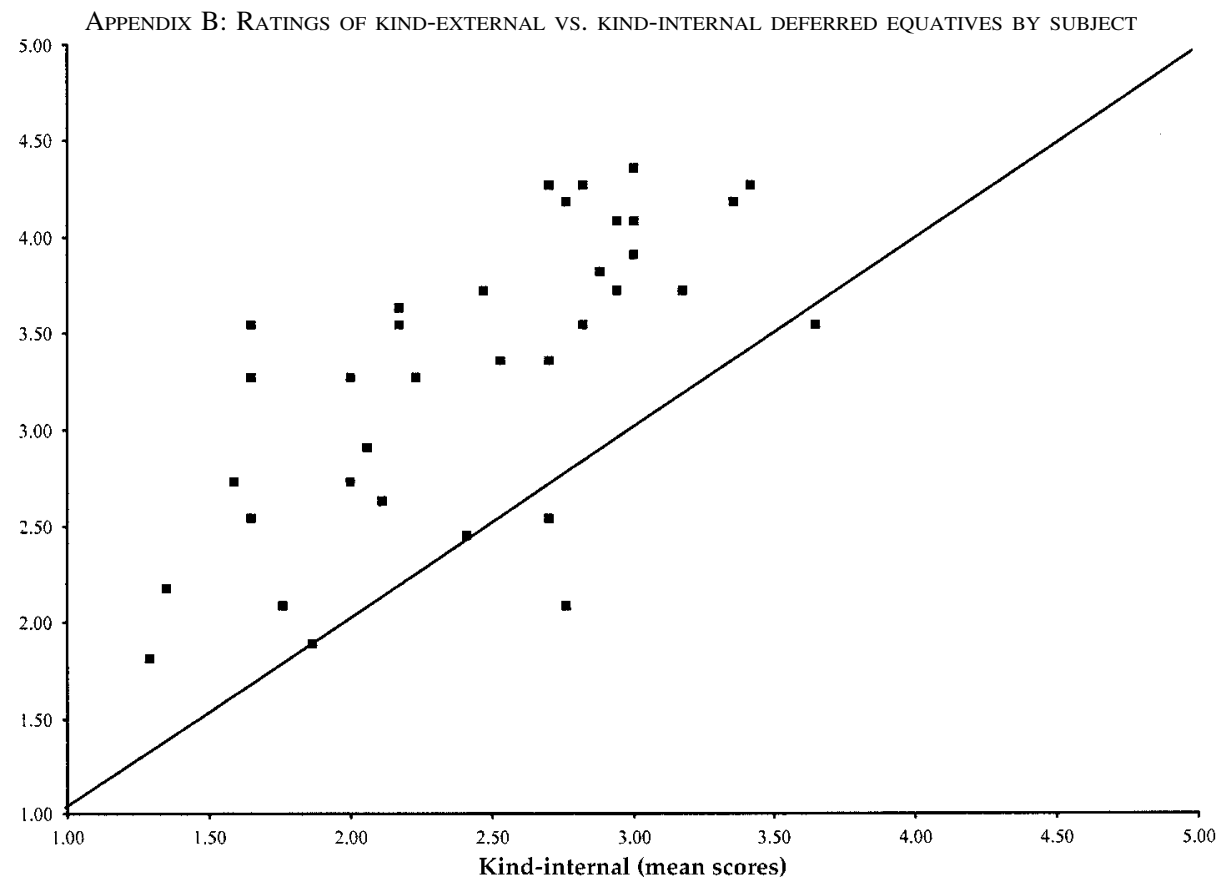

\section{REFERENCES}

Aвbott, Barbara. 2004. Definiteness and indefiniteness. Handbook of pragmatics, ed. by Laurence R. Horn and Gregory Ward, 122-49. Oxford: Blackwell.

APRESJAN, Juri D. 1974. Regular polysemy. Linguistics 142.5-32.

ARIEL, MiRa. 1990. Accessing noun-phrase antecedents. London: Routledge.

Birner, Betty J.; JefFrey P. Kaplan; and Gregory Ward. 2001. Open propositions and epistemic would. Paper presented at the annual meeting of the Linguistic Society of America, Washington, DC, January 2001.

Birner, Betty J., and Gregory Ward. 1994. Uniqueness, familiarity, and the definite article in English. Berkeley Linguistics Society 20.93-102.

BirNER, BetTy J., and GREGORY WARD. 1998. Information status and noncanonical word order in English. Amsterdam: John Benjamins.

Burzio, Luigi. 1992. On the morphology of reflexives and impersonals. Theoretical analyses in Romance linguistics, ed. by Christiane Lauefer and Terrell Morgan, 399-414. Amsterdam: John Benjamins.

Сномкку, NoAm. 1971. Deep structure, surface structure, and semantic interpretation. Semantics: An interdisciplinary reader in philosophy, linguistics, and psychology, ed. by Danny Steinberg and Leon Jakobovits, 183-216. Cambridge: Cambridge University Press.

Clark, Herbert H. 1977. Bridging. Thinking: Readings in cognitive science, ed. by Philip Johnson-Laird and Peter Wason, 411-20. Cambridge: Cambridge University Press.

Copestake, Ann, and Ted Briscoe. 1995. Semi-productive polysemy and sense extension. Journal of Semantics 12.15-67.

Fauconnier, Gilles. 1994. Mental spaces. Cambridge, MA: MIT Press.

Geach, Peter T. 1962. Reference and generality. Ithaca: Cornell University Press.

Grice, H. Paul. 1975. Logic and conversation. Syntax and semantics 3: Speech acts, ed. by Peter Cole and Jerry Morgan, 41-58. New York: Academic Press.

Grosz, Barbara, and Candace L. Sidner. 1986. Attention, intentions, and the structure of discourse. Computational Linguistics 12.175-204.

Gundel, Jeanette, and Thorstein Fretheim. 2004. Topic and focus. Handbook of pragmatics, ed. by Laurence R. Horn and Gregory Ward, 175-96. Oxford: Blackwell. 
Gundel, Jeanette; Nancy Hedberg; and Ron Zacharski. 1993. Cognitive status and the form of referring expressions in discourse. Language 69.274-307.

Hawkins, John A. 1978. Definiteness and indefiniteness. Atlantic Highlands, NJ: Humanities Press.

Hawkins, John A. 1991. On (in)definite articles: Implicatures and (un)grammaticality prediction. Journal of Linguistics 27.405-42.

Heycock, Caroline, and Anthony Kroch. 1997. Inversion and equation in copular sentences. ZAS Papers in Linguistics 10.71-87.

Higgins, Francis Roger. 1979. The pseudo-cleft construction in English. New York: Garland.

JACKENDOFF, RAY. 1972. Semantic interpretation in generative grammar. Cambridge, MA: MIT Press.

JACKENDOFF, RAY. 1978. Grammar as evidence for conceptual structure. Linguistic theory and psychological reality, ed. by Morris Halle, Joan Bresnan, and George A. Miller, 201-28. Cambridge, MA: MIT Press.

JACKENDOFF, RAY. 2002. Foundations of language: Brain, meaning, grammar, evolution. Oxford: Oxford University Press.

Joseph, BRIAN D. 1979. On the agreement of reflexive forms in English. Linguistics $17.519-23$.

KadMON, NiRit. 1990. Uniqueness. Linguistics and Philosophy 13.273-324.

KadmON, Nirit. 2001. Formal pragmatics. Oxford: Blackwell.

KEHLER, ANDREW, and GREGORY WARD. 1999. On the semantics and pragmatics of 'identifier $s o$ '. The semantics/pragmatics interface from different points of view (Current research in the semantics/pragmatics interface 1), ed. by Ken Turner, 233-56. Amsterdam: Elsevier.

Kehler, Andrew, and Gregory Ward. 2004. Constraints on ellipsis and event reference. Handbook of pragmatics, ed. by Laurence R. Horn and Gregory Ward, 383-403. Oxford: Blackwell.

KRIPKE, SAUl. 1972/1980. Naming and necessity. Oxford: Blackwell.

Kuno, Susumu. 1973. The structure of the Japanese language. Cambridge, MA: MIT Press.

Lakoff, George, and Mark Johnson. 1980. Metaphors we live by. Chicago: University of Chicago Press.

LAMBRECht, KNUD. 1994. Information structure and sentence form. Cambridge: Cambridge University Press.

Langacker, Ronald. 1984. Active zones. Berkeley Linguistics Society 10.172-88.

Leech, Geoffrey. 1974. Semantics. Harmondsworth, UK: Penguin Books.

LEwIS, DAvid. 1979. Scorekeeping in a language game. Journal of Philosophical Logic 8.339-59.

LiDZ, JeFFrey. 2001. Condition R. Linguistic Inquiry 32.123-40.

Lieber, Rochelle. 1990. On the organization of the lexicon. New York: Garland.

MiLl, John Stuart. 1848. A system of logic, ratiocinative and inductive; being a connected view of the principles of evidence and the methods of scientific investigation. New York: Harper \& Brothers.

Norvig, Peter, and George Lakoff. 1987. Taking: A study in lexical network theory. Berkeley Linguistics Society 13.195-205.

Nunberg, Geoffrey. 1977. The pragmatics of reference. New York: City University of New York dissertation.

Nunberg, Geoffrey. 1979. The non-uniqueness of semantic solutions: Polysemy. Linguistics and Philosophy 3.143-84.

Nunberg, Geoffrey. 1995. Transfers of meaning. Journal of Semantics 12.109-32.

Ostler, Nicholas, and B. T. S. Atkins. 1992. Predictable meaning shift: Some linguistic properties of lexical implication rules. Lexical semantics and knowledge representation, ed. by James Pustejovsky and Sabine Bergler, 87-100. Berlin: Springer.

Partee, Barbara H. 1978. Bound variables and other anaphors. Proceedings of TINLAP2, 79-85.

Postal, Paul. 1969. Anaphoric islands. Chicago Linguistic Society 5.205-39.

Prince, Ellen F. 1981. Toward a taxonomy of given/new information. Radical pragmatics, ed. by Peter Cole, 223-54. New York: Academic Press. 
Prince, Ellen F. 1986. On the syntactic marking of presupposed open propositions. Chicago Linguistic Society 22.208-22.

PrinCE, ElLEN F. 1992. The ZPG letter: Subjects, definiteness, and information-status. Discourse description: Diverse analyses of a fundraising text, ed. by Sandra Thompson and William Mann, 295-325. Amsterdam: John Benjamins.

Pustejovsky, James. 1995. The generative lexicon. Cambridge, MA: MIT Press.

Recanati, François. 2003. Literal meaning. Cambridge: Cambridge University Press.

Roberts, CRAIGE. 2003. Uniqueness in definite noun phrases. Linguistics and Philosophy 26.287-350.

Rochemont, Michael. 1986. Focus in generative grammar. Amsterdam: John Benjamins.

Russell, Bertrand. 1905. On denoting. Mind 14.479-93.

SAG, Ivan. 1981. Formal semantics and extralinguistic context. Radical pragmatics, ed. by Peter Cole, 273-94. New York: Academic Press.

Sidner, CANDACE. 1979. Towards a computational theory of definite anaphora comprehension in English discourse. Cambridge, MA: MIT dissertation.

STAllard, DaVid. 1993. Two kinds of metonymy. Proceedings of the 31st annual meeting of the Association for Computational Linguistics, 87-94. Columbus, OH: Association for Computational Linguistics.

VALLDUVí, EnRIC. 1992. The informational component. New York: Garland.

Verspoor, Cornelia Maria. 1997. Contextually-dependent lexical semantics. Edinburgh, UK: University of Edinburgh dissertation.

Ward, Gregory. 1988. The semantics and pragmatics of preposing. New York: Garland.

Ward, Gregory; Richard Sproat; and Gail McKoon. 1991. A pragmatic analysis of socalled anaphoric islands. Language 67.439-74.

Ward, Gregory, and Sam Tilsen. 2002. Deferred equatives. Paper presented at the annual meeting of the Linguistic Society of America, San Francisco, January 2002.

Webber, Bonnie L. 1979. A formal approach to discourse anaphora. New York: Garland.

Department of Linguistics

Northwestern University

2016 Sheridan Road

Evanston, IL 60208-4090

[gw@northwestern.edu]
[Received 5 September 2002;

revision received 5 June 2003; accepted 21 November 2003] 